\title{
There Is No Alibi in Designing: Responsibility and Dialogue in the Design Process
}

\author{
Thomas-Bernard Kenniff* and Ben Sweeting ${ }^{\dagger}$
}

This paper explores a potential relation between architecture and ethics intrinsic to design processes when understood in terms of dialogue or conversation. We draw on separate but related research interests: one focused on the design process, especially the significance of drawing, and the other on the ethics of designing for the public realm, with reference to Bakhtinian dialogism. Our investigation concentrates on two aspects of the design process both of which can be thought of in terms of conversation - first, the relation between architect and Other, and second, the act of drawing. Through this, we support the idea that in design the ethical and the aesthetic cannot be meaningfully separated from one another. Instead, their relation must be understood as a dialogue in and of itself, as well as part of the dialogue between all participants in the design process.

\section{Introduction}

In this paper we explore what we identify as a deep potential relation between architecture and ethics intrinsic to design processes. That is, we see ethics as consisting of a dialogue: the process of discovering, evaluating and contesting what is better or worse in any given situation, as opposed to the resolution of that particular situation in a way understood as being ethically 'correct' (however this might be defined). In this way we aim to position our discussion in contrast to works on ethics in architecture that have gravitated toward either professional responsibility; technological issues; specific moral issues (for example, sustainability or participation); or aesthetic judgement (for example, the debate on ornamentation).

\footnotetext{
* The Bartlett, UCL, UK, and Carleton University, Canada

tb.kenniff@ucl.ac.uk

+ University of Brighton and The Bartlett,

$\mathrm{UCL}$, UK

r.b.sweeting@brighton.ac.uk
}

Through comprehending dialogue as manifest in designing architecture, we understand architectural design as a way of doing ethics. ${ }^{1}$

We understand the principles of dialogue and conversation with reference to our separate, but related, research projects. One is focused on the design process-especially the significance of drawing-with reference to Pask's conversation theory (1976) as developed by Glanville (2007) in terms of design. The other focuses on the ethics of designing for the public realm, with reference to Bakhtinian dialogism as it applies to urban design theory and practice. ${ }^{2}$ Building on these sources, we focus our investigation on two aspects of the design process: first, the relation between architect and Other; and second, the act of drawing. Through exploring these topics, we show that the design process is as much ethical as it is aesthetic (see also Findeli 1994; Leach 2005; and Till 2009) and that consequently, in a dialogical conception of design, the ethical and the aesthetic cannot be separated from each other in any meaningful way. The relation between 
the ethical and the aesthetic can be understood as dialogue in and of itself, as well as part of the dialogue between all participants in the design process. That is, our sense perception of the world in time and space cannot meaningfully be separated from our valued relationships to other human beings.

As the idea for this article came from wanting to have a conversation about these convergent points of our respective research projects, its structure reflects the idea of dialogue. The article's sections thus follow the pattern of statement, first response, second response and open discussion (where both voices are closely intertwined).

\section{Designer and Other}

Within any design project, particularly those in or for the public realm, there exists a range of methods used by designers (often in conjunction with other actors like the municipality) to engage with the project's potential and existing publics. Some of these are standard and institutionalised, like consultation or planning applications. Some are less standard and depend on the main participants' willingness to explore alternate ways of developing the project, for example through public art projects, public exhibitions, or collaborative exercises. Some methods are intrinsic to the design process and do not require direct engagement, including imagining future activities; abstracting people to movement patterns or functional programmes; statistical analysis; or inventing personas to play out possible scenarios in the future space. Overall, these varying levels of engagement relate to historically developed methods like consultation, participation, user-centred design, collaborative work, or shared-authorship. These methods serve to balance the asymmetry of the design process by opening it up to other people, giving voice to those who may have been otherwise excluded from the process, or challenging the monologic authority and certainty of a single voice.

In order to concentrate on defining the relationship between designer and Other in its broadest terms, we start with the simplest question: what takes place when someone designs for somebody else? More specifically, what sort of responsibility is at play in the act of designing for the Other? We capitalise Other to emphasise the sense of otherness that is felt regardless of whether a designer is dealing with a single private client, or multiple heterogeneous publics. In all cases, the act of design means encountering complex relationships with Others situated outside the self. This means that design is inescapably inter-subjective: a dialogue structured according to valued relationships between participants (both real and imagined).

Mikhail Bakhtin is one of the foremost dialogical thinkers alongside Martin Buber and Emmanuel Levinas. His work rests on the principle that it is impossible to conceive of any entity outside of the relations that link it to an other; what Todorov (1984: 94) summarised as 'the dialogical principle.' Bakhtin's work is of particular relevance to design if we understand design to be inter-subjective, for his early work amounts to a theory of creative activity based on alterity, dialogue and open-ended processes. At its core is the belief that everything that has meaning and significance is dialogical, that is, meaning is the result of an open-ended dialogue between various entities (Bakhtin 1984: 34). Meaning and value, in this case, are never given, but always worked at through a process of deliberation, negotiation, agreement and disagreement, changing over time and space.

What the creative act does, according to Bakhtin (1993), is turn this dialogue into form (turning theory into practice). To act is to come out of oneself once and for all, to take position vis-à-vis an internal or external dialogue and implies the acknowledgement of one's answerability for the action (Bakhtin 1993: 28). For Bakhtin, every individual occupies a unique position in time and space that cannot simultaneously be occupied by somebody else. That is, one's actions affirm the uniqueness of one's position in the world, a condition Bakhtin refers to as the "nonalibi in Being' (40). The act therefore holds 
tremendous importance in this theory of creative activity because it is the enactment of an embodied and valued relationship to the Other, and one that makes us answerable for our unique positions in the world.

The various methods used to open up design to the Other (participation, consultation, exhibitions, etc.) are ways of addressing relationships in the project by giving them value. Independent of quality considerations, we understand that a contract between designer and client, or a participatory workshop with local residents, both contribute to the value of the relationships. Furthermore, designers are constantly involved in exercises that invent publics and users by putting values on the relationships they have with others in the process (whether real or imagined). When designers put pen to paper, so to speak, and make design decisions, they are shaping valued relationships into form (a proposal, a strategy, a detail). Designing is thus analogous to Bakhtin's 'act'. It is an enactment of valued relations in the design process (between designer and users, clients and other stakeholders) and of the unique position of the designer in time and space with respect to Others.

What Bakhtin's theory of the act tells us is that alterity is a necessary condition of the creative process (Bakhtin 1990: 86). As we saw, the inter-subjectivity of every act-particularly every design act-means that no creation is possible without dialogue.

\section{Designer and Drawing}

As well as thinking about the relationship between designers and those they design for as a dialogue, it is also possible to understand the activity of designing (manifest in actions such as drawing and sketching) in similar terms. An analogy between design and conversation has been suggested by Cross (2007), Gedenryd (1998), Goldschmidt (1991) and Schön, who referred to design as a 'reflective conversation with the situation' (1991: 76). ${ }^{3}$ One way in which this analogy can be substantiated is via the understanding of circularity in cybernetics (see for instance
Glanville 2007, 2009; Krippendorff, 2007). Cybernetics is a discipline concerned with circular interaction and feedback and so with the structure of dialogue or conversationespecially in Pask's (1976) Conversation Theory and in von Foerster's (1991, 1992, 2003) cybernetic approach to ethics. This shared interest makes comparisons with Bakhtin possible, as have been suggested by Krippendorff (1996).

Drawing particularly on Pask's (1976) Conversation Theory, Glanville (2007) shows how the circularity of conversation is similar in structure to designing - particularly with regard to one of the most characteristic component activity of designing, sketching. ${ }^{4}$ While many insights about design can be gained from this analogy between design and conversation (see for instance Glanville 2007 and Gedenryd 1998), our aim in this section is to describe design's implicitly dialogical structure. In doing so, we suggest there is a deep reciprocity between design activity and the wider dialogues in which designers participate.

It is a premise of Conversation Theory that meaning cannot be transferred from one participant to another. ${ }^{5}$ Given this, the question arises how it is possible for us to communicate stable meanings with one another as we evidently can do. This can be explained in terms of the circular feedback (that is, cybernetic) mechanisms that occur in conversation. When participating in conversation we compare the meaning that we try to communicate with what we understand other participants have understood in terms of what they say back to us. If these two meanings (what I meant to communicate; what I understand the other to have understood) are close then we can be satisfied that we have been understood well enough to continue. If the meanings are divergent, we can offer further clarification or explain ourselves in different ways, and again compare what we mean to say with what we understand has been understood. We can keep repeating this process in order to bring these two meanings closer together (see similarly von Foerster, 
1991: 72-73, 2003) - or, alternatively, until we agree to disagree (Pask, 1988: 55). In the cybernetic understanding of conversation, our communication takes the recursive form 'what I think of what you think I think, etc.' (Glanville, 1993: 217) allowing us to share ideas with each other while our understandings remain independent (there is no transference of meaning; we do not need to know for sure what the other thinks).

The mechanism of conversation is more than just a way of communicating static meaning - it is also a generative process that helps us invent new understandings and improve existing ones through interaction with others. This is most obvious in the way we learn from the ideas which others present to us and from their comments on, and criticisms of, our own thoughts, which prompt us to revise our thinking. As well as this, we also learn through this interaction where we discover what our own ideas imply by seeing how they are interpreted by others or where we sometimes learn through misunderstanding where others see a worthwhile idea in what we say which we had not intended.

The activity of designing is, similarly to a conversation, a circular process of feedback. While this can be seen to work at different scales throughout design, it is particularly evident in sketching where the feedback is most immediate. In sketching the designer simultaneously plays role of speaker and listener, switching roles between the two while evaluating and drawing at the same time. ${ }^{6}$ This process is also present in the more long term tasks of the design process, such as developing different iterations of a scheme, but in a more clearly sequential manner. Similarly to a conversation, the circularity of design enables both the pursuit of stability and also the generation of new ideas and goals. In sketching, the designer needs to continually invent new understandings at every turn (continually constructing possible ways of interpreting the sketch), receives feedback about an idea through its exploration (in the same way that we learn from the other) and finds new ideas in a drawing even when not intended (in the same way that in a conversation a misunderstanding can sometimes offer new possibilities). While in one sense the feedback process of sketching allows us to pursue a particular idea, as with conversation, this idea is not fixed at the outset but is developed through the process. In trying to achieve some idea, we revise not just the attempt to fulfil it but also the idea itself, having learnt more about it and the situation, just as the nature and content of a conversation changes during its course. Designers in this sense do not solve problems but invent them, exploring the situation through making proposals.

Drawings play an important role in enabling a dialogue between designers and users, opening up the project so that it can be commented on. The value of drawing for designers, however, is not just as a means of communicating ideas or of enabling others to participate in the design process but, also, in sustaining designers' own internal dialogues. Sketching is like a conversation whereby the designer simultaneously plays both the roles of speaker and listener. The designer anticipates the Other by 'walking through' the plans, etc., using drawings (and the activity of drawing) to imagine how the proposal would be experienced in the position of the other - in a comparable sense to what von Foerster calls seeing 'through the eyes of the Other' and which he connects to ethics (1991, 2007: 267). This 'Othering' of the self, made possible by working through a medium such as when sketching, is important not just, ethically, in terms of considering others in the process but also for designers' own exploration of the complex situations which they typically encounter. ${ }^{8}$ That is, dialogue with Others is not solely a participatory exercise to be added onto design but integral to it (and more generally how one acts in the world). It is only by looking 'through the eyes of the Other' that one sees what one has done and what this means. 


\section{Design and Dialogue}

The preceding two sections were founded on two different premises, the first on the inter-subjective nature of existence and the second on the circular structure of drawing. Still, both sections offer similar conclusions: all modes of design (from sketching to participatory methods) are modes of relating to Others; the nature of this relation is dialogical (it is not fixed, but open-ended); and finally, every design act involves (at some point) occupying a position outside the self. Our goal in the final part of this article is to develop these ideas through setting them up in conversation, so to speak. Our aim is to show that one crucial predication of understanding design as dialogue is through the reciprocity, and mutual equivalence, of the ethical and the aesthetic.

Our work has demonstrated that in either the context of the relation between designer and drawing, or between designer and Other, the process of designing is both ethical and aesthetic. Design's dialogical structure incorporates ethical and aesthetic considerations in its internal processes, such as drawing, and its outward looking ones, such as engagement with others. Ethical and aesthetic issues are connected in two ways. First, a connection arises in the act of designing, as the process involves the consideration of perceivable properties (aesthetics) and of other people (ethics). Second, there are ethical and aesthetic connections in the structure of dialogue: while our ethical relation with the Other is enacted in conversation, this process presupposes an aesthetic relation, whether between designer and drawing or designer and another person.

The importance of occupying a position outside the self in dialogue stems from our spatial embodiment in the world-we exist as unique observers in the world and this uniqueness means we can never see ourselves completely (Todorov 1984: 95). However, this means that I see things that others cannot, what Bakhtin expresses as the excess of seeing' (1990: 22). This excess is what I give to the Other and what the Other gives to me so that we may temporarily create a more holistic-although unavoidably still incomplete-vision of the self. This occurs in conversation by enabling participants to see both the topic and themselves from different perspectives-we see ourselves as situated in the world by understanding how someone else has understood us.

In both dialogism and cybernetics then, a crucial aspect of dialogue is that it enables us to see ourselves from other points of view, whether in conversation, via the drawing, or in the empathy of anticipating the Other. Yet in both cases, the experience of a position outside the self is always followed by a return to the self. For Bakhtin, this return is the beginning of aesthetic activity and supports any act of authorship, hence the necessity for, and the inevitable presence of, the Other in creative acts (1990: 25). This double movement of departure and return is understood by cybernetics in terms of circularity, as feedback connections such as those in a conversation between the self and others. In the activity of drawing, it is the medium that supports outside-ness and conversation: it is because one experiences the drawing that one can judge how to improve it.

The double movement (or circularity) of aesthetic activity is a foundation for ethics in both dialogic (Gardiner 1996, Murray 2000, Nealon 1997) and cybernetic thought (von Foerster 1991, 2003; Glanville 2004). The dialogue of positioning and re-positioning one's actions (in cybernetic terms: feedback) both connects us with, and is our primary mode of relating to, the Other. Responsible (or answerable) evaluation and action cannot meaningfully be separated from our perception of the world, or, in other words, the ethical cannot be separated from the aesthetic. They are joined in dialogue; first because deliberation and values are enacted in dialogue through perceivable actions, and second, because aesthetics is the foundation of embodied relations to Others in the world. It follows from understanding design as 
dialogue that neither ethical judgement nor aesthetic considerations can be isolated. The designer's responsibilities are tied to both ethics and aesthetics, and are furthermore implied in actions that affirm the designer's unique position in the world. Therefore, in the same way that there can be no alibi in Being, there can be no alibi in designing.

We can see in both the examples discussed above (the dialogical relations between the designer and the drawing, and those between the designer and the Other) an understanding of ethics as being concerned with processes, rather than with particular solutions. Given this, a critical question is not how a particular conversation can be resolved, but how it can be maintained in such a way that it is productive. In writing this paper, we found the most productive moments were those when, after going over a few drafts, we found passages that were neither fully one or other of ours, something that challenged both our initial positions and the development of our ideas. This discovery supported the necessity for capturing the productive uncertainty intrinsic to dialogical processes, for it is the quality of dialogue that matters more than its acknowledgment. In this sense, focusing on dialogical processes and allowing unexpected development and outcomes works to reinforce the critique of systemic or structural approaches that leave no room for either doubt or response. Thinking about design in this way means a shift of emphasis from the application of given tools, the following of strict guidelines or the entrenchment in absolute positions, to negotiation and deliberation about what might constitute 'good' design in varying contexts. Indeed, what is appropriate to one situation may not be for the next. Diminishing aesthetic concerns in order to emphasise an ethical design process is as problematic as negating the significance of Others in order to emphasise aesthetic coherence or individual genius. Controversial calls for 'less aesthetics, more ethics' are equally problematic, then, as calls for 'more aesthetics, less ethics'. ${ }^{9}$

\section{Notes}

${ }^{1}$ On the responsibility of authority implied in any instance of doing ethics, see Somerville (2009: 4-5).

${ }^{2}$ Research in urban design is supported by an in-depth investigation of the recent Barking Town Square in East London. The Town Square, completed in 2010, is a mixed-use project in the London Borough of Barking and Dagenham with buildings by AHMM and public space by muf architecture/art. The latter is recognised, significantly for our research, in terms of its dialogical approach to social engagement in urban design, which mixes public art practice with architectural practice. Although comments in this paper are supported by three years of research, including extensive fieldwork in Barking, there is unfortunately no space to expand on this evidence. For further elaboration see Kenniff $(2011,2012)$.

${ }^{3}$ The process described by Goldschmidt (1991) as dialectic is, in terms of our argument in this article, better understood as dialogue.

${ }^{4}$ Sketching is also the most prominent example taken by Gedenryd (1998), Goldschmidt (1991) and Schön (1991) in describing the epistemology of design in terms of conversation. It is a microcosm of the design process as a whole.

${ }^{5}$ For a fuller account of Conversation Theory than is possible here, see Barnes (2007), Glanville (1993), Glanville and Müller (2007) and Scott (2001, 2007).

${ }^{6}$ In Pask's Conversation Theory (1976) a distinction is drawn between the participants in a conversation (psychological-individuals) and their embodiment (mechanical-individuals). These distinctions are not necessarily in a one-to-one correspondence and thus I, for example, can play the role of several participants in dialogue with myself, as in the example of drawing. Similarly, dialogue in Bakhtin does not necessarily mean another human being is present. Conversation can happen between a designer 
and imagined users, which means there is only one human. Dialogic relations, Bakhtin contends, are present in everything, even monologues (Bakhtin 1986, also Casarino and Negri 2008). The intersubjectivity inherent to dialogism is the acknowledgement of the alterity that characterises each person in becoming.

${ }^{7}$ Lawson's (1979) studies show how in problem solving situations designers focus on proposing potential solutions rather than, as scientists, on analysing the problem. Designers explore the situation through making proposals. See also Cross (2007: 36-37).

${ }^{8}$ On the importance of working through a medium to the way designers think, see, for instance, Gedenryd, 1998 and Sweeting, 2011.

9 'Less Aesthetics, More Ethics' was the title given to the 2000 Venice Architecture Biennale by its director Massimiliano Fuksas (see Leach 2005).

\section{References}

Bakhtin, M M 1990 Art and Answerability: Early Philosophical Essays. Austin: University of Texas Press.

Bakhtin, M M 1984 Problems of Dostoevsky's Poetics. Minneapolis: University of Minnesota Press.

Bakhtin, M M 1986 Toward a Methodology for the Human Sciences. In Emerson, $\mathrm{C}$ and Holquist, $\mathrm{M}$ (eds.) Speech Genres and Other Late Essays pp. 159-172. Austin: University of Texas Press.

Bakhtin, M M 1993 Toward a Philosophy of the Act. Austin: University of Texas Press.

Barnes, G 2007 Education in Mind. In Glanville, R and Müller, K H (eds.) Gordon Pask, Philosopher Mechanic: An Introduction to the Cybernetician's Cybernetician pp. 65-96. Vienna: Edition Echoraum

Casarino, C and Negri, A 2008 In Praise of the Common: A Conversation on Philosophy and Politics. Minneapolis: University of Minnesota Press.

Cross, N 2007 Designerly Ways of Knowing. Basel: Birkhäuser
Findeli, A 1994 Ethics, Aesthetics, and Design. Design Issues, 10(2): pp. 49-68. DOI:http://dx.doi.org/10.2307/1511628

Gardiner, M 1996 Alterity and Ethics: A Dialogical Perspective. Theory Culture Society, 13(2): pp. 121-143. DOI: http://dx.doi. org/10.1177/026327696013002009

Gedenryd, H 1998 How Designers Work, Making Sense of Authentic Cognitive Activities. Lund: Lund University

Glanville, R 1993 Pask: A Slight Primer. Systems Research, 10(3): pp. 213-218. DOI: $\quad$ http://dx.doi.org/10.1002/sres. 3850100326

Glanville, R 2004 Desirable Ethics. Cybernetics \& Human Knowing, 11(2): pp. 77-88.

Glanville, R 2007 Try Again. Fail Again. Fail Better: The Cybernetics in Design and the Design in Cybernetics. Kybernetes, 36(9/10): pp. 1173-1206. DOI: http:// dx.doi.org/10.1108/03684920710827238

Glanville, R 2009 A (Cybernetic) Musing: Design and Cybernetics. Cybernet ics and Human Knowing, 16(3/4): pp. 175-186.

Glanville, R and Müller, K H (Eds.) 2007 Gordon Pask, Philosopher Mechanic: An Introduction to the Cybernetician's Cybernetician. Vienna: Edition Echoraum.

Goldschmidt, G 1991 The Dialectics of Sketching. Creativity Research Journal, 4(2): pp. 123-143. DOI: http://dx.doi. org/10.1080/10400419109534381

Kenniff, T-B 2011 Bakhtinian Dialogism as Framework for Participant Architectural Research. In Plowright, P and Gamper, B (eds.) Considering Research pp. 169-178. Detroit, MI: Lawrence Technological University.

Kenniff, T-B 2012 Identity in Peripheries: Barking and its Others. In Morrow, R and Abdelmonem, G (eds.) Peripheries pp. 40-53. London: Routledge.

Krippendorff, K 1996 A Second-Order Cybernetics of Otherness. Systems Research, 13(3): pp. 311-328. DOI: http://dx.doi.org/10.1002/(SICI)10991735 (199609) 13:3<311::AID SRES106>3.0.CO;2-O 
Krippendorff, K 2007 The Cybernetics of Design and the Design of Cybernetics. Kybernetes, 36(9/10): pp. 13811392. DOI: http://dx.doi.org/10.1108/ 03684920710827364

Lawson, B R 1979 Cognitive Strategies in Architectural Design. Ergonomics, 22(1): pp. 59-68. DOI: http://dx.doi. org/10.1080/00140137908924589

Leach, N 2005 Less aesthetics, More Ethics. In Ray, N (ed.) Architecture and its Ethical Dilemmas pp. 135-142. London: Taylor \& Francis.

Murray, J W 2000 Bakhtinian Answerability and Levinasian Responsibility: Forging a Fuller Dialogical Communicative Ethics. Southern Communication Journal, 65(23): pp. 133-150. DOI: http://dx.doi.org/ 10.1080/10417940009373163

Nealon, J T 1997 The Ethics of Dialogue: Bakhtin and Levinas. College English, 59(2): pp. 129-148. DOI: http://dx.doi. org/10.2307/378545

Pask, G 1976 Conversation Theory, Applications in Education and Epistemology. Amsterdam: Elsevier Publishing Co.

Pask, G 1988 Learning Strategies, Teaching Strategies, and Conceptual or Learning Style. In R. R. Schmeck (Ed.), Learning Strategies and Learning Styles pp. 83-100. New York, NY: Plenum Press. DOI: http://dx.doi.org/10.1007/978-14899-2118-5_4

Schön, D A 1991 The Reflective Practitioner: How Professionals Think in Action. Farnham: Arena, Ashgate Publishing Limited. Originally published 1983.
Scott, B 2001 Gordon Pask's Conversation Theory: A Domain Independent Constructivist Model of Human Knowing. Foundations of Science, 6(4): pp. 343360. DOI: http://dx.doi.org/10.1023/ A: 1011667022540

Scott, B. 2007 The Cybernetics of Gordon Pask. In R Glanville \& K H Müller (Eds.), Gordon Pask, Philosopher Mechanic: An Introduction to the Cybernetician's Cybernetician pp. 29-52. Vienna: Edition Echoraum.

Somerville, M A 2009 The Ethical Imagination: Journeys of the Human Spirit. Montreal: McGill-Queen's University Press.

Sweeting, B 2011 Conversing with Drawings and Buildings: From Abstract to Actual in Architecture. Kybernetes, 40(7/8): pp. 1159-1165. DOI: http://dx.doi.org/ 10.1108/03684921111160386

Till, J 2009 Architecture Depends. Cambridge, MA: MIT Press.

Todorov, T 1984 Mikhail Bakhtin: The Dialogical Principle. Manchester: Manchester University Press.

von Foerster, H 1991 Through the Eyes of the Other. In Steier, F (ed.) Research and Reflexivity pp. 63-75. London: Sage Publications.

von Foerster, H 1992 Ethics and Secondorder Cybernetics. Cybernetics and Human Knowing, 1(1): pp. 9-19.

von Foerster, H 2003 Objects: Tokens for (Eigen-)Behaviors. In Understanding Understanding pp. 261-272. New York: Springer-Verlag. Originally published 1977.

\footnotetext{
How to cite this article: Kenniff, T-B and Sweeting, B 2013 There Is No Alibi in Designing: Responsibility and Dialogue in the Design Process. Opticon1826, (16): 1, pp. 1-8, DOI: http:// dx.doi.org/10.5334/opt.bj
}

Published: 6 January 2014

Copyright: (c) 2013 The Author(s). This is an open-access article distributed under the terms of the Creative Commons Attribution 3.0 Unported License (CC-BY 3.0), which permits unrestricted use, distribution, and reproduction in any medium, provided the original author and source are credited. See http://creativecommons.org/licenses/by/3.0/. 